\title{
LOS DESAFIOS DEL AGUA. LA PRODUCCIÓN ELÉCTRICA COMO FACTOR DE DESEQUILIBRIO ECONÓMICO REGIONAL
}

\author{
Cipriano Juárez Sánchez-Rubio \\ Universidad de Alicante
}

\section{RESUMEN}

La disponibilidad de agua determina la capacidad de crecimiento económico del territorio. La regulación de los caudales hídricos ha sido estrategia esencial para garantizar el fomento del regadío, como primera necesidad, el abastecimiento urbano y el progreso industrial. La transferencia de energía eléctrica sin compensación económica ha generado un modelo de articulación territorial más desigual y desequilibrada. Las provincias menos desarrolladas y exportadoras deberían haberse beneficiado del efecto multiplicador del agua en la producción hidroeléctrica y las nucleares pero vieron relegado sus intereses a favor de las regiones/ provincias más desarrolladas hacia donde se ha dirigido su consumo con la consiguiente mejora del PIB, la generación de empleo, el aumento demográfico y el peso político. Un modelo de articulación territorial más desigual, menos equilibrado y solidario necesitado de cambio.

Palabras clave: Política hidráulica, embalses reguladores, regadío, electricidad, transferencia, poder económico y desarrollo sostenible.

El agua, recurso renovable, es el elemento básico del desarrollo sostenible. Este comporta crecimiento económico y calidad de vida en equilibrio con los recursos de agua. El gran desafío radica en armonizar el desarrollo con la sostenibilidad. Por tanto, se debe garantizar el suministro de agua para aumentar la producción agraria, el abastecimiento urbano y la producción hidroeléctrica sin condicionar el futuro de las generaciones venideras. Todo esto, sin olvidar los impactos previsibles del cambio climático y las acciones que deben acometer los gobiernos para crear infraestructuras y una economía sostenible. Es hora de abandonar las discusiones estériles y empezar a concentrarnos en los desafíos 
reales del agua (agua y agricultura sostenible, el cambio climático y el agua y agua y energías renovables) y cumplir el Objetivo de Desarrollo Sostenible para superar las desigualdades y reducir las diferencias económicas entre las áreas rurales y urbanas.

La regulación de los caudales hídricos ha sido estrategia esencial para mejorar los rendimientos agrícolas y sostener a la población.Un salto cualitativo en la relación agua-crecimiento se ha producido cuando las posibilidades técnicas han permitido un aprovechamiento más intensivo del recurso para usos que han ido marginando progresivamente los débitos orientados hacia la agricultura en beneficio de la producción hidroeléctrica ${ }^{1}$. Aprovechamiento del agua que no ha sido neutro sino que ha perseguido fines políticos. En concreto, durante el período de autarquía de 1939-1959, la política hidráulica se orientó hacia el agrarismo conforme a la necesidad de asegurar la producción agrícola, desoyendo el alto interés social que tenía la generación de la electricidad. Una obligación de todos los gobiernos de la Unión Europea de asegurar la producción agrícola que dependía más que en la actualidad de las condiciones naturales y de las fluctuaciones de los precios.

Esta contribución tiene la tarea de averiguar, conocer y proponer nuevas estrategias de carácter público que beneficien tanto el mejor aprovechamiento de los recursos eléctricos en las zonas consumidoras como crear incentivos para mejorar la economía y el medio ambiente de los territorios cedentes. Se trata de corregir estos intereses, amparados en los ideales de cambio de la sociedad, según los patrones doctrinarios que, desde la Ley de Aguas de 1879, han pasado desde el reformismo liberal, al regeneracionismo de la Segunda República, al franquismo sustituido luego por el mercantilismo neoliberal y al capitalismo sin beneficio alguno para las provincias exportadoras de energía: Cáceres, Salamanca, Zamora, Orense, Guadalajara, Huesca, etc., perjudicadas por el peligro de albergar las presas y las centrales nucleares.

\section{LA POLÍTICA HIDRÁULICA AL SERVICIO DEL CAMBIO SOCIOECONÓMICO}

La investigación científica en general y la geográfica en particular han de estar al servicio de la sociedad. La región es considerada como el espacio de desarrollo económico y organizado donde existen potencialidades que ofrecen posibilidades de aprovechamiento y limitaciones. En España la relación existente entre

1. Ponce, G y JuAREZ, C. (2015). «Del agro-franquismo al electro-franquismo: las grandes infraestructuras hidráulicas al servicio de los modelos socioeconómicos en la España de la Dictadura (1939-1975).- III Simposio Internacional de historia de la electrificación. México. En «Obras hidroeléctricas, redes y energías alternativas». Editorial del Instituto de Investigaciones Dr. José María Luis Mora, el Instituto de Geografía de la UNAM y la Universidad Autónoma Metropolitana (en publicación). También en http://www.ub.edu/geocrit/iii-mexico/ponce.pdf. Pag.1 
territorio y economía ha generado la España rica frente a la España pobre. Un problema que se trató de corregir en la dictadura franquista mediante los Planes de Desarrollo, los Polos de crecimiento y los Polos de desarrollo. Diferencia de renta y riqueza entre las regiones españolas que ha cristalizado en un desarrollo económico desequilibrado de difícil situación para salir de la crisis que ha agravado las desigualdades y acentúa los desequilibrios regionales. La región con renta más alta en 2014 es Madrid con 31004 euros mientras Extremadura es la menor con 15720 euros, el 50,7\%. Extremadura exportadora de energía eléctrica es la única Comunidad Autónoma española por debajo del 75\% del PIB de la media de la UE. Ocupa el lugar 221 de 273 autonomías frente a Madrid en el puesto 41. Características que se hacen extensivas al País Vasco cuya diferencia con Extremadura también se ha aumentado durante la crisis de 2008-2013.

El agua siempre ha jugado un papel importante en la historia agraria de nuestro país, sobre todo, desde mediados del siglo xix a la actualidad. La política hidráulica que se ha realizado en España se apoya en la Ley de Aguas de 1879, que permitía la utilización racional del recurso para mejorar la condición económica y social del conjunto de la población. El desarrollo de las áreas rurales pasa por la explotación racional de los recursos. La política española en el medio rural desde finales del siglo xviII se ha definido por dos criterios: económico-productivo (obras hidráulicas, regadío) y el político social (reforma de las estructuras de la propiedad), plasmados en las actuaciones de la política hidráulica, la colonización, la ordenación rural etc.

La cantidad de agua que recibe el territorio peninsular español es prácticamente constante y teóricamente suficiente para atender el desarrollo de las actividades productivas, a pesar de la profunda transformación económica, demográfica, social y paisajística, desde la segunda mitad del siglo xx a la actualidad. Sólo un problema mediatiza esta suficiencia, superficial y subterránea, la desigual distribución de los recursos hídricos renovables en el espacio y en el tiempo. La falta de concordancia entre los ritmos de las precipitaciones y de las temperaturas ha conducido a la necesidad de controlar las corrientes superficiales de agua, reteniéndolas mediante presas, almacenándolas en embalses y desviándolas mediante canales hacia lugares no inmediatos de consumos. Todavía están en uso los embalses romanos de Proserpina y Cornalvo, los de mayor antigüedad de los existentes en y fuera de nuestro país, con los que consiguieron los colonos romanos dar agua a los habitantes y huertos de Emérita Augusta al elevar los caudales afluyentes del Guadiana a la ciudad ${ }^{2}$. Embalses que se multiplican en el tiempo por el apoyo de las entidades locales y sobre la base de pequeñas presas muy localizadas: extremeñas, alicantinas, murcianas etc.

2. Juarez, Sanchez-Rubio C. (1979). Caracteres climáticos de la cuenca del Guadiana y sus repercusiones agrarias. Universidad de Salamanca. Salamanca pág. 17. 
Sin embargo, este modelo constructivo cambia en el tiempo inducido por las propuestas de la política hidráulica, al considerar la ampliación de la superficie de regadío como la forma más eficaz para mejorar la riqueza, la nutrición y la capacidad de trabajo del país. El Estado asume la construcción de las grandes obras hidráulicas frente a la iniciativa privada que apenas había actuado. Por ello, propone entre las soluciones a la crisis de España la mayor explotación de la riqueza hidráulica natural y la gestión estatal de las obras y su aprovechamiento que hasta entonces habían sido llevadas por la iniciativa privada. Necesidad de una ordenación hidráulica del territorio, fundamental para su modernización agraria, ya que la mayor parte de la población radicaba en el campo, dependiendo de la agricultura por no haberse producido en España la revolución industrial del siglo XIX. Atraso económico de España que despertó el interés de aprovechar de forma extensiva e intensiva al agua.

En consecuencia, el aprovechamiento del agua no ha sido neutro, sino que ha perseguido fines políticos. En concreto, desde la Ley de Aguas de1879 hasta finales de la década de los años cincuenta la política hidráulica se ha orientado hacia el agrarismo confirmado mediante el Primer Plan Nacional de Aprovechamientos Hidráulicos de 1902 (también denominado Plan Gasset). Este no era nada más que un catálogo de obras que señalaba los lugares aparentemente propicios para cortar un valle y modificar las condiciones económicas del país. No se procedió a un estudio de la distribución de las precipitaciones, su irregularidad, la cuantía de los recursos disponibles, las condiciones agrológicas y la capacidad de agua útil del suelo (Centro de Estudios Hidrográficos 1933, pág. 21). El Plan incluía la construcción de 296 obras que posibilitarían el riego de 1.469.022 ha, la mitad de las cuales correspondería a la cuenca del Guadiana, 406602 ha y 327000 ha a la del Ebro. Pero la ausencia de los estudios necesarios no hacía posible la transformación de la superficie contemplada en la cuenca del Guadiana porque su disponibilidad máxima era de $2092 \mathrm{hm}^{3}$ que sólo aportarían $5145 \mathrm{~m}^{3}$, volumen insuficiente para acometer un cultivo de regadío rentable 3 .

En cambio, más eficaces fueron los esfuerzos de las compañías privadas para la construcción de embalses y saltos de agua que habían de integrarse en las redes eléctricas. La generación hidroeléctrica quedaba relegada a un sector privado fuertemente regulado que se expandió en una forma que excedía las previsiones del Plan de 1902. Fruto de este esfuerzo es que en veinte años se quintuplicó la potencia instalada pasando de 190.000 kilowatios en 1901 a

3. JuÁREZ, C (1973). «La acción planificadora del Estado en las Vegas del Guadiana.V Pleno del Consejo Económico y Social de Badajoz, pag.19-20.»Las finalidades del Plan Badajoz eran: regulación del Guadiana mediante cinco presas con una capacidad de embalse de $3245 \mathrm{hm}^{3}$ para garantizar una disponibilidad de $1000 \mathrm{hm}^{3}$ /año, transformación en regadío de 105000 ha, colonización de la zona transformada e industrialización de las posibles producciones de las tierras regables. 
957.000 en 1920. Se pone ya de manifiesto el claro desequilibrio existente entre las cantidades de agua embalsadas para fines industriales y las de uso agrario ${ }^{4}$.

Sin embargo, desde finales de los años cincuenta del siglo xx la estrategia expansiva del regadío comienza a ponerse en tela de juicio. En España empiezan a plantearse problemas análogos a los de los países que tienen un poblamiento medio, precipitaciones no abundantes en la mayor parte del territorio y ciertas zonas de concentración industrial ${ }^{5}$. Ya no es la agricultura la que demanda grandes volúmenes de agua, sino que cada vez se requiere mayores proporciones para consumo de los grandes núcleos urbanos y para las crecientes necesidades de industrialización. Se inicia el período álgido de la producción y consumo hidroeléctrico, en relación con la dinámica del desarrollo industrial de las regiones españolas, que se alarga hasta la segunda mitad de los años setenta por las crisis del petróleo y su precio.

La teoría y la política del desarrollo regional concentrado surgen y se difunden durante los años sesenta del siglo xx sobre la base de un paradigma funcional de difusión espacial del crecimiento. Después de este período de fuerte concentración productiva se ha ido conformando un contexto de desarrollo endógeno basado en la utilización de los recursos locales, situando al territorio en el centro de interés de la problemática social y económica. Se trata de intentar reducir las diferencias municipales de renta y empleo mediante la utilización de los recursos por sus residentes para mejorar su condición económica y social. Por ello, en la actualidad las estrategias de desarrollo se plantean cada vez más desde las estructuras territoriales en las que inciden, de forma relevante, los contenidos de los espacios geográficos. Esto obliga a realizar un diagnóstico de la situación actual de desequilibrio económico entre las regiones productoras y exportadoras de energía eléctrica para diseñar una serie de objetivos que se deben alcanzar en el futuro inmediato y mejorar la relación entre el territorio y la economía.

Estos cambios en la economía y en la sociedad junto a las importantes transformaciones en los procesos urbanos y la aparición de nuevas demandas sociales suponen nuevos retos para las provincias exportadoras de energía eléctrica. La situación de desequilibrio económico comporta tanto una revisión de las estrategias de los factores de progreso como una generación de políticas adaptadas al desarrollo sostenible sobre la base de la competitividad económica, la cohesión social y el respeto al medio ambiente. La necesidad de tener una perspectiva estratégica del territorio, a diferentes escalas, en los albores del siglo XXI, dominado

4. Diaz Marta, M. (1969). Las obras hidráulicas en España. Ed. Agrupación Europeísta de México.México, pag. 39.

5. Morales,A y Juarez, C. (1981). Cambio en los usos del agua. Estudios Geográficos n. ${ }^{\circ} 165$ pag. 380 . 
por la globalización, obliga a realizar un diagnóstico. Coherentemente con este se deben fijar los objetivos de un desarrollo más equilibrado entre los territorios que soportan las infraestructuras eléctricas y no reciben ninguna compensación económica (provincias deprimidas) y las que se benefician de la producción (desarrolladas). Y es que las transferencias eléctricas generan un modelo de articulación territorial desigual, poco equilibrado y solidario que se debe materializar en medidas fiscales para la sostenibilidad. Es necesario y obligado valorar tanto el mantenimiento del medio ambiente como la producción de la energía hidroeléctrica, principal fuente renovable, de las provincias exportadoras.

ASIGNACIÓN DE RECURSOS DE AGUA PARA EXPANSIÓN DEL REGADÍO COMO VANGUARDIA DE MODERNIZACIÓN AGRARIA, CRECIMIENTO ECONÓMICO Y VERTEBRACIÓN DEL TERRITORIO

El aprovechamiento agrario del suelo en secano (cereal, olivo y vid) depende más de la oportunidad de las precipitaciones que de la cantidad total anual recibida. Este tipo de agricultura es de baja rentabilidad económica y elevada irregularidad productiva. El Estado asumió la dirección de la economía que se hizo rural, rompiendo la tendencia migratoria a las ciudades. No hubo capital suficiente para acometer el plan de modernización, tecnificación e irrigación del campo español que siguió soportando su tradicional retraso. Esta falta de inversión y las pertinaces sequías de los años cuarenta provocaron la carestía de alimentos. En España, por término medio, una hectárea de regadío produce siete veces más que la misma superficie de secano, genera una renta cinco veces superior y la capacidad de trabajo por unidad transformada es tres o cuatro veces más alta. Efecto multiplicador que la transformación en regadío tiene sobre la productividad del suelo cultivado y el nivel de vida de la población. El regadío se convierte en la vanguardia del proceso de modernización agraria por la mejora económica, la generación de empleo, la fijación de la población y la vertebración del territorio.

Las Leyes de Agua de la segunda mitad del siglo XIX favorecen las actuaciones de empresas capitalistas para la transformación en regadío. Sin embargo, el interés mostrado por la iniciativa privada ha sido pequeño al aumentar la superficie regada en unas 80.000 hectáreas entre 1874 y 1902. La rentabilidad económica era baja porque se tardaba de 15 a 20 años para que la superficie transformada fuera productiva. El movimiento regeneracionista propone, entre las soluciones a la crisis del 98, la mayor explotación de la riqueza hidráulica y la gestión estatal de las obras y su aprovechamiento que hasta entonces habían sido llevadas por la iniciativa privada.

El paisaje hidráulico de España varía significativamente desde la puesta en práctica de la política hidráulica. Esta tenía como principio central la necesidad 
de proporcionar agua suficiente para todos aquellos agentes sociales capaces de utilizarla en el desarrollo de la producción. Un proceso que implicaba la transformación del territorio mediante el conocimiento geográfico y la financiación pública, en el caso de que la iniciativa privada no quisiera asumir ningún riesgo. El interés de J. Costa por la obra hidráulica y la puesta en riego promovida por el Gobierno,(en contra de la promoción privada anterior), como medio de mejorar los rendimientos agrarios, se plasma en el Plan de Obras Hidráulicas de 1902 cuyo plazo de ejecución se extendería hasta 1923. Costa asume como ideal un plan de colonización por el Estado que se haría cargo de las obras hidráulicas, la transformación en regadío y la concesión de parcelas a nuevos propietarios. Un proceso de asentamiento por parte del Estado de agricultores en zonas asignadas en regadío, mediante la concesión de parcelas cultivables y viviendas públicas que se hizo efectivo en el franquismo, 1939-1975, pasando de una política de regadío a una política de colonización.

En 1902 la superficie regada en España era de 1.231.094 ha (Ministerio de Agricultura y Obras Públicas. Dirección General de Agricultura, 1904, pag. 267). El estado no fomentó la expansión del regadío hasta la Ley del 7 de julio de 1911 para grandes regadíos (modificada en 1925) que inaugura una verdadera política de riegos al asumir el Estado los proyectos de los pantanos y canales para fomentar la riqueza nacional teniendo en cuenta las condiciones agronómicas de las zonas regables, donde se regula la actividad constructora con auxilio de los entes interesados, con asociaciones o por su propia iniciativa. El pantano de Alarcón (río Júcar), con capacidad de 1118 hm³ , es la obra hidráulica acometida por los Usuarios del Júcar (regantes, industriales, compañías eléctricas) en auxilio del Estado. Embalse regulador que en la actualidad juega un papel fundamental como infraestructura del trasvase Tajo -Segura para el abastecimiento y uso agrario de las provincias de Alicante, Murcia y Almería. En la cola de este pantano se mezclan las aguas del Tajo con las del Júcar que van al Segura.

La Ley de grandes regadíos de 1911 seguía insistiendo en la vocación agraria de las grandes obras de infraestructuras privadas (por ser prioritarias conforme con el pensamiento liberal de la época), pero también de la nuevas obras públicas, al considerar que la iniciativa privada era insuficiente para las grandes transformaciones agrarias que necesitaba el país. Desde esta Ley el Estado deja de ser mero donante de ayudas a los particulares y se otorga la facultad de construir directamente las obras necesarias para tal fin. Las modificaciones de 1925, a la Ley de 1911, tenían por objetivo aumentar el control público sobre el recurso agua para mitigar las tensiones para usos agrarios e industriales de mayor aportación al crecimiento económico de la nación. Por tanto, se imponía la gestión estatal al del recurso agua para fomentar tanto al regadío como a la producción hidroeléctrica, en manos de las compañías privadas. 
La política hidráulica alcanza con la Ley de Puesta en Riego Urgente (Ley OPER) de 1932 y la Asamblea sobre «Las directrices de los riegos de Levante», celebrada en Alicante, la expresión más intensa de la Segunda República. El Plan de Obras Hidráulica de 1933 hacía hincapié en el interés económico nacional de la expansión del regadío en el Sureste peninsular: Alicante, Murcia y Almería. El desarrollo de una verdadera política hidráulica estatal comportaba la necesidad de mejorar tanto la iniciativa en el medio rural, que no había logrado grandes avances, como el desarrollo de la industria hidroeléctrica fuera de la acción directa del Estado que aportaba más a la economía española ${ }^{6}$. Se imponía la gestión estatal del recurso para favorecer la producción hidroeléctrica en combinación con los regadíos (Plan Nacional de Obras Hidráulicas de 1933). Aprovechamiento integral del agua que continúa en los sucesivos planes posteriores porque las demandas superan la mitad de los recursos naturales (II Plan de Desarrollo,1968-72).

Sin embargo, las circunstancias históricas de 1936-1939 frenó la dinámica transformadora del regadío, que entre 1935-1950 tan solo supuso 57.000 has (Cuadro n. ${ }^{\circ}$ 1), mientras la producción hidroeléctrica se mantuvo baja hasta 1950 e incluso descendiera en los años de sequía. La cantidad de agua embalsada para uso agrario sólo aumenta cuando el Estado asume como prioridad estratégica la transformación en regadío mediante los Planes de Badajoz de 1952, el Plan Jaén de 1953, el Plan del Campo de Gibraltar y el Plan de La Tierra de Campos, de 1966-71. Se pasa de un volumen regulado de $3935 \mathrm{hm}^{3}$ en 1940 a $36.628 \mathrm{hm}^{3}$ en 1970. La obra colonizadora pretendía la creación de empresas agrarias de orientación agrícola, capaces de conseguir un nivel productivo que posibilitara la retención de la mano de obra familiar y de obreros agrícolas en el campo, pero que no lo ha conseguido, aunque el impacto producido tiene aspectos positivos ${ }^{7}$. El número de núcleos de población construidos a finalizar el proceso colonizador es de 246. La instalación de colonos en secano y regadío y obreros agrícolas por el INC-IRYDA es de 53.601 y el número de viviendas total, agrupadas y dispersas es de $29666^{8}$. En 1975 Andalucía, Extremadura y Aragón acaparaban el $75 \%$ de las tierras transformadas, el $75 \%$ de los nuevos colonos y obreros agrícolas y el $70 \%$ de los nuevos núcleos de población que se eleva casi al $80 \%$ cuando se incluye a Castilla y León? .

6. Pardo, L. (1933). Plan Nacional de Obras Hidráulicas. Cap. III, p. 3.

7. JuÁrez, C y Rodríguez, M. (1996). «Efectos de la política de colonización en el regadío de Extremadura». Investigaciones Geográficas n. ${ }^{\circ} 16$, pag. 35.

8. Ortega, N. (1979). Política agraria y dominación del espacio. Ed. Ayuso.Madrid, pp 240 y 248.

9. JuÁrez, C. (1998). Agua y regadío en España. Etapas, objetivos y resultados. Revista de Extremadura n. ${ }^{\circ} 25$, enero-abril, p. 44. 
Cuadro 1. Relación capacidad agua embalsada (millones $\mathrm{m}^{3}$ ) y superficie regada (miles $\mathrm{Ha}$ )

\begin{tabular}{|l|c|c|c|c|c|c|c|c|}
\hline & $\mathbf{1 9 0 0}$ & $\mathbf{1 9 3 1}$ & $\mathbf{1 9 5 0}$ & $\mathbf{1 9 5 5}$ & $\mathbf{1 9 6 0}$ & $\mathbf{1 9 6 5}$ & $\mathbf{1 9 7 0}$ & $\mathbf{1 9 7 5}$ \\
\hline Regadío & 1077 & 1393 & 1450 & 1456,3 & 1828,3 & 2055 & 2198,4 & 2616,8 \\
\hline $\begin{array}{l}\text { Agua } \\
\text { embalsada }\end{array}$ & 97,7 & 4033,4 & 6445 & 11831 & 17314 & 22876 & 36628 & 39165 \\
\hline Relación $\mathbf{~ m}^{3} / \mathbf{H a}$ & 90,7 & 2895,5 & 4444,8 & 8124,0 & 9470,0 & 11131,9 & 16661,2 & 14966,8 \\
\hline
\end{tabular}

Fuente: INE, Ponce-Juárez, 2015.

Las posibilidades y condiciones del desarrollo de los territorios están vinculadas a la gestión y uso del agua en el sector agrario como fuente de ingresos económicos y generación de empleo, la producción hidroeléctrica, el proceso industrial y el turismo como una de las estrategias de futuro. Había que lograr crear un sistema que permitiera una visión global del agua como factor estratégico para un desarrollo económico y social armónico de las regiones españolas para no aumentar la desigualdad y pérdida de oportunidades. Los embalses juegan un importante papel como reguladores de caudales para suministro urbano, uso agrario, aprovechamiento hidroeléctrico y en la laminación de las avenidas (según Iberdrola, reducen un 50\% el número de avenidas que se producirían en condiciones naturales).

El régimen natural hidrológico sólo aprovecha $9190 \mathrm{hm}^{3} /$ año mientras la capacidad reguladora en el 2015 es de $55.977 \mathrm{hm}^{3}$, el $50 \%$ de la aportación de todos los ríos del país, de la que el $40 \%$ es de uso exclusivo de la producción hidroeléctrica Sin embargo, este proyecto hidráulico para uso agrario e hidroeléctrico deja de ser punta de lanza del progreso económico en 1971 cuando se sustituye el INC por el IRYDA y se aprueba el Plan Eléctrico de 1971 que abandona las posibilidades hidroeléctricas y se confía en las nucleares. Pero la construcción de presas ha continuado porque están justificadas en los aspectos técnicos, económicos y ecológicos ya que los embalses son una necesidad social por la poca lluvia y su y desigualdad en el territorio. En las cuencas del Tajo, Guadiana y Segura la capacidad de almacenamiento es superior a las aportaciones naturales de un año.

La política hidráulica de alcance estatal, intervención directa del Estado en la construcción de presas y canales, estaba orientada a favorecer el desarrollo del regadío como factor estratégico para mantener el crecimiento demográfico, uno de los más altos de Europa Occidental, radicar de forma estable a la población y superar la endémica pobreza del campo español. El regadío es un sistema agrario en el que intervienen la política agraria (función económica), la política de desarrollo rural (función social) y la política hidráulica (función ambiental) y cuyo objetivo es el incremento del bienestar de la sociedad. El fomento de 
la superficie en regadío comportaba un aumento continuado de la capacidad de embalses. Las presas han constituido el motor de la economía española. El volumen de agua embalsada aumentó poco hasta los años cincuenta. Entre 1950-1970 la capacidad crece más que el número de presas por construirse grandes reservorios. El aumento de la capacidad de embalse se produce tanto por las acciones de Estado (expansión del regadío) como por el aprovechamiento hidroeléctrico bajo la iniciativa privada. Pero el mayor crecimiento de agua embalsada se produce en los años sesenta, relegada la política de regadíos a un segundo plano frente a la prioritaria industrialización (Planes de Desarrollo) y el abastecimiento urbano (Cuadro n. ${ }^{\circ} 2$ ).

El agua embalsada tenía como objetivo prioritario garantizar la producción hidroeléctrica para las zonas industriales del País Vasco, Madrid, Cataluña, etc. Por ello, la relación entre capacidad de embalses y la superficie regada es cada vez más desequilibrada. Pero, cuando se analizan ambas acciones reguladoras no deben ser consideradas conjuntamente como resultado de la aplicación de la política hidráulica ya que la iniciativa privada sólo construye y explota embalses con fines hidroeléctricos mientras el Estado lo hace para aumentar el regadío. Lejos, por tanto, del calificativo de superabundante que pudiera considerarse al utilizar como variable representativa el volumen total de la capacidad de embalse. Y es que, el agua almacenada en los embalses hidroeléctricos no contribuye en nada a solucionar los problemas de escasez del país ${ }^{10}$. Aprovechamiento hidroeléctrico exclusivo que explica el $40 \%$ de la capacidad de embalse, cuyo porcentaje aumenta hasta el $60 \%$ cuando el concepto utilizado es el de volumen regulado. En cambio, los embalses del Estado, regulando y distribuyendo el caudal de los ríos que atraviesan la España semiárida, constituyen la base fundamental de la economía hidráulica nacional.

La política expansiva del espacio regado con base a las recomendaciones de la FAO en 1958-1959 comienza a ponerse en tela de juicio en 1960, al tiempo que se empieza a admitir la imposibilidad real de que la política colonizadora, por sí sola, sea capaz de solucionar el problema del campo. La colonización agraria se entiende como el proceso de asentamiento, por parte del Estado, de agricultores en zonas asignadas en regadío, mediante la concesión de parcelas cultivables y viviendas públicas. Un balance desigual porque la más beneficiada ha sido la gran propiedad agraria al confirmarse que casi el $70 \%$ de las tierras transformadas en regadío han quedado en mano de sus antiguos propietarios frente al 30\% entregada a los colonos. Por esto, el Informe del Banco Mundial de 1962 proponía poner fin a las prácticas desarrollistas de la acción colonizadora y la construcción de grandes embalses para riego, atendiendo las previsiones de

10. Torrent, L. (1987). «Los aprovechamientos hidroeléctricos en los planes hidrológicos». II Jornadas de Energía Hidráulica, p. 6. Oviedo. 
industrialización y urbanización de la sociedad española para corregir tanto la despoblación del campo como las desigualdades regionales.

La creación del IRYDA en 1971 cambia la filosofía y los objetivos de la política agraria estatal hacia: el desarrollo rural, una vez que la colonización dejó de ser prioritaria por haber cumplido sus fines. El regadío no constituye una solución definitiva para resolver los problemas de desequilibrio regional. El aumento de la superficie regada se corresponde con un mayor aprovechamiento de las aguas subterráneas de iniciativa privada (soportan regadíos de más altos rendimientos) y los trasvases que reparten y llevan el agua donde la naturaleza no la da. Las campiñas y valles de la Meseta (Castilla y León y Castilla La Mancha), Campo de Dalías, Campo de Níjar y litoral onubense en Andalucía ${ }^{11}$ junto al trasvase Tajo- Segura son las zonas beneficiadas. Nuevo espacio regado que incorpora las técnicas más avanzadas: invernaderos y el riego localizado. Agricultura de vanguardia sostenible, rentable, exportadora en un mundo globalizado, generadora de empleo y fijadora de población en el medio rural que es motor de desarrollo económico y social.

Cuadro 2. Evaluación de la capacidad de embalse y transformación en regadío

\begin{tabular}{|c|c|c|c|c|}
\hline Año & $\begin{array}{l}\text { Capacidad del } \\
\text { embalse }\left(\mathrm{hm}^{3}\right)\end{array}$ & $\%$ & $\begin{array}{l}\text { Ha en regadío } \\
\text { (mill/ha) }\end{array}$ & $\%$ \\
\hline 1900 & 98 & 100 & $1^{\prime} 08$ & 100 \\
\hline 1940 & 3.935 & 4.016 & $1 ' 40$ & 129 \\
\hline 1950 & 6.445 & 6.576 & 1,45 & 134 \\
\hline 1960 & 17.314 & 17.667 & 1,82 & 168 \\
\hline 1970 & 36.628 & 37.375 & 2,19 & 202 \\
\hline 1975 & 39.165 & 39.964 & 2,61 & 241 \\
\hline
\end{tabular}

Fuente: INE, Ponce-Juárez, 2015.

Por esto, razones estrictamente económicas y de generación de empleo, también políticas, propias del modelo desarrollista y de la situación específica del sureste peninsular español(escasez de agua en relación con las posibilidades productivas) impulsa la realización del trasvase Tajo-Segura al considerar a la fachada litoral de las provincias de Alicante, Murcia y Almería como una reserva geográfica que interesaba promocionar para el desarrollo turístico-residencial, el desarrollo industrial y agrario. Cambio en el uso del agua (fig. 1) que invita

11. CruZ, J (1996). «El mapa político de la colonización en Andalucía» Investigaciones Geográficas, n. ${ }^{\circ} 16$, p. 29. 
Figura 1. Planes de regadío y desarrollo industrial (1950-1975)

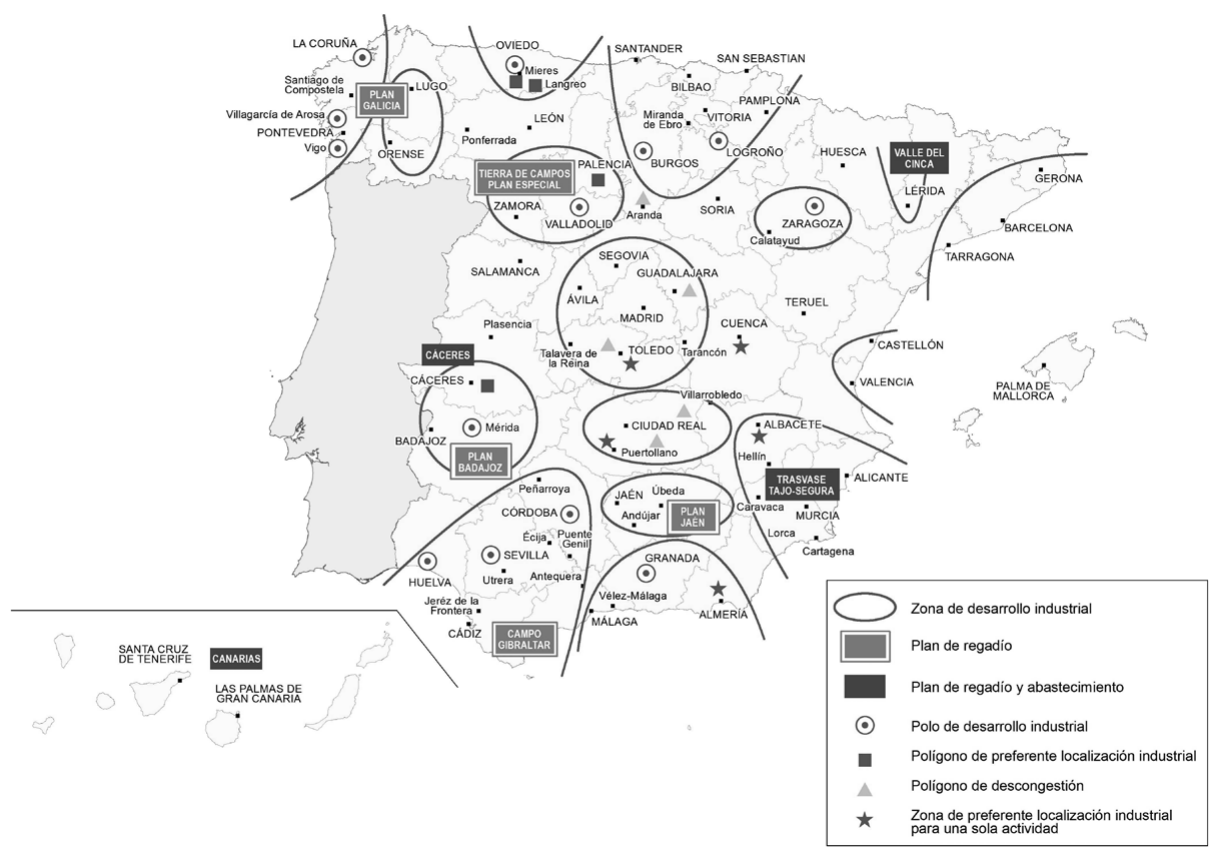

Fuente: Comisaría de Planes de Desarrollo. Ministerio de Industria. Elaboración propia.

a pensar que el trasvase tenía más sentido industrial y urbano que agrícola ${ }^{12}$. Proceso de cambo geográfico que individualiza al sector litoral de las provincias de Alicante, Murcia y Almería respecto al conjunto del Postrasvase, significándole como un área de privilegio en el general desajuste del crecimiento económico del territorio beneficiado por los caudales regulados, excedentes y procedentes del río $\mathrm{Tajo}^{13}$.

La expansión del regadío ha ido perdiendo importancia económica hasta dejar de ser elemento fundamental de la riqueza nacional aunque sigue siendo de un gran interés para mejorar la estructura productiva del territorio. Entre 1940 y 1970 se ha multiplicado entre nueve y diez veces la capacidad de los embalses, mientras la superficie regada ha crecido solamente el 56\% (Cuadro n. ${ }^{\circ}$ 2).El suelo ocupado por el regadío ha seguido creciendo hasta 3,4 millones

12. SÁNCHEZ, M., et alli (1975) Estudios Económicos. Región de Valencia. Induban. Valencia pp. 52. También, Morales y Juárez, op,cit, pp 395. También, El País 9-10-1977. Igualmente Fig. 1. 13. JuÁrez, C. (1991). Planificación Hidrológica y desarrollo económico: El Trasvase TajoSegura, Instituto de Cultura «Juan Gil-Albert». Alicante, pag. 146. 
de hectáreas en 1996, el primer país de Europa, seguida de Italia con 3,1. En el 2014 la superficie regada se eleva a 3,6 Mill. Superficie regada inferior a los casi 4,5 Mill., considerada por el Plan de Lorenzo Pardo en 1933 (1,39 Millo. transformadas y los 3,048 Millones de posible ampliación). Es decir, 81 años después sólo se ha puesto en regadío el $81 \%$ de lo estimado. En cambio, el consumo de agua para riego está disminuyendo al pasar de $17.681 \mathrm{hm}^{3}$ en 1999 a 15.833 en 2012. Los nuevos sistemas de riego han ahorrado $1848 \mathrm{hm}^{3}$ pero los regadíos necesitan mayor consumo energético, por lo que los costes de producción por hectárea cultivada han aumentado considerablemente (la luz representa el $40 \%$ de los costes del agua). Se demanda que el regadío pueda producir energía distribuida y generar electricidad en su zona regable para autoconsumo, conocida como balance neto, que ya se utiliza en otros países de Europa y permite además inyectar a la red nacional la producción que no se necesite ${ }^{14}$

El regadío ha dejado de ser elemento fundamental para el fomento de la riqueza nacional aunque sigue siendo de un gran interés económico para mejorar la estructura productiva agraria. La superficie de regadío en el 2014 es de 3.605.121 has. Genera el 65\% de la producción agrícola bruta, supone el $2 \%$ del PIB español, da empleo al $4 \%$ de la población ocupada en España, tiene como principales cultivos a los cereales con el $28 \%$, el olivar con el $21 \%$, el viñedo con el 10\%, los cítricos con el $8 \%$ y los frutales no cítricos con el 7,5\%. Las comunidades con más superficie regada son: Andalucía con 30\%, Castilla-La Mancha, 14\%, Castilla y León 12\%, y Aragón con el 11\%. El sistema de riego más eficiente es el localizado usado en el $49 \%$ de los campos.

La transformación del espacio regado ha supuesto la posibilidad de fijar más la población en el medio rural y mantener el territorio. La superficie regada puede aumentar hasta 5 Millones de hectáreas y la capacidad de embalse hasta $60.000 \mathrm{hm}^{3}$ Sin embargo, el regadío no puede ser el único sistema productivo para asegurar la calidad de vida de la población rural. Se trata de garantizar el cumplimiento de la Ley 45/2007 de Desarrollo Sostenible del Medio Rural que asegure el crecimiento económico, la utilidad social y la protección del medio ambiente. La gestión del agua ha de constituir un ejercicio de solidaridad para solucionar los desequilibrios regionales. La sociedad debe saber que para obtener un producto agrícola se necesitan entre 4000 y $6000 \mathrm{~m}^{3} / \mathrm{ha} /$ año de lluvia o de riego. Pero la sociedad urbana desconoce, por lo general, el valor productivo del agua en la agricultura, en el equilibrio territorial y en el asentamiento de la población. Las zonas rurales que ganan y mantienen más población son aquellas

14. Ambientum.com 25/02/ 2014. Más de 4000 regantes exigen una factura eléctrica adaptada a su consumo. También, Fandos, J.L. «El Plan Badajoz está amortizado y pagado varias veces por los regantes». En GaviRIA, M et alli. Extremadura Saqueada. Ruedo Ibérico. Paris/ Barcelona 1978, p. 433. La producción eléctrica obtenida es inseparable del riego y debe ser propiedad de los regantes. 
en la que existe mayor dinamismo económico debido a la extensión del regadío $\mathrm{y}$ a la agroindustria, frente a los territorios de secano.

De lo expuesto, se concluye que la política hidráulica seguida en España hasta 1960 ha tenido su desafío en la expansión del regadío como vanguardia de modernización agraria, del crecimiento económico, la fijación de la población y la vertebración del territorio. Sin embargo, la política del desarrollo rural de la UE ha evolucionado continuamente para responder a los nuevos retos de las zonas rurales mediante la diversificación de las actividades económicas de los lugares. El desarrollo rural durante los últimos 25 años no ha frenado el abandono de la población ni la sobreexplotación del agua. Ahora que se quiere fomentar de nuevo el Desarrollo Rural, mediante la diversificación de las actividades económicas de los lugares, es el momento de poner en valor todos los recursos endógenos, sustentar todos los procesos de cambio, la transformación socioeconómica, la paisajística y la territorial.

La garantía de disponibilidad de agua es el mayor indicador de calidad de vida de un país, de un pueblo y de una familia. Se debe garantizar la satisfacción de la demanda de agua, principal obligación de los poderes públicos, para abastecimiento urbano de los núcleos rurales y la creación de empleo. Pueblos enteros con grandes dificultades para acceder al agua tienen limitado su desarrollo mientras localidades más pequeñas, pero sin problemas de abastecimiento y riego tienen todo un surtido de diversas entidades burocráticas y financieras. La presa de La Serena (Guadiana) es un elemento básico de la política de aguas: abastece a 350.000 personas, aporta agua para los regadíos de las Vegas del Guadiana (Plan Badajoz), tiene instalada una central de energía hidroeléctrica, permite regular las avenidas por lluvias torrenciales del Zújar (caudal de agua desbordante), abre un gran abanico de posibilidades en el uso turístico del territorio y contribuye eficazmente a cumplir el Convenio de Albufeira, de 1998, entre España y Portugal. La puesta en funcionamiento del túnel entre los embalses de Zújar y Orellana, a partir de la cota 295 m por diferencia de nivel, convierte prácticamente en un solo embalse los separativos del tradicional sistema Cijara-Zújar ${ }^{15}$. Modificaciones de la geografía que tienen una gran repercusión económica, social y medioambiental haciendo más habitable el territorio.

Es hora de abandonar las disensiones y concentrarnos en los desafíos del agua para cumplir el objetivo de Desarrollo Sostenible mediante la asignación de fondos de diferentes unidades para reducir la desigualdad. Los desafíos hídricos deben ser tanto un asunto de solidaridad (los trasvases son necesarios, factibles y viables aunque no son la única solución) como la necesidad de una

15. JuArez, C. (2004). «La función de los hiperembalses del sistema Cijara-Zújar en el cambio hidrológico del Guadiana y sus afluentes», en A. Gil Olcina (coord.) Alteración de los regímenes fluviales peninsulares, Cajamurcia, Murcia, pp. 525-553. 
política de agua de uso racional y sostenible, inspirada en los principios de la equidad y la sustentabilidad como la mejor forma de futuro de la explotación integral del recurso.

UN NUEVO DESAFÍO: CAMBIO CLIMÁTICO, AGUA Y DESARROLLO RURAL SOSTENIBLE

En España, desde los años sesenta del siglo Xx se asocia el consumo de agua con el desarrollo económico y el nivel de vida. El aumento de la demanda de agua ha sido considerado como indicador de progreso, riqueza económica y calidad de vida de sus habitantes. La previsible disminución de los recursos de agua por el cambio climático obligará a coordinar la planificación hidrológica y gestión de los recursos renovables con la territorial y agraria para garantizar el desarrollo local, la equidad social y la protección del medioambiente de las diferentes Comunidades Autónomas. Es necesario conocer para prever y actuar sobre el cambio climático y paliar su vulnerabilidad (Fig n. $\left.{ }^{\circ} 2\right)$.

La relación entre cambio climático y agua es unitaria. La gestión del agua de una cuenca o demarcación hidrográfica se inicia por cuantificar los recursos renovables para después establecer su modelo de uso sostenible. Las adversas condiciones climáticas sufridas en los últimos años han dado y están dando como resultados que algunas cuencas hidrográficas españolas continúen con acusados problemas para el suministro de agua, tanto para abastecimientos a las poblaciones como para el aprovechamiento agrario y ganadero, por lo que

Figura 2. Cambio climático y desafío del agua

CAMBIO CLIMÁTICO Y DESAFÍO DEL AGUA

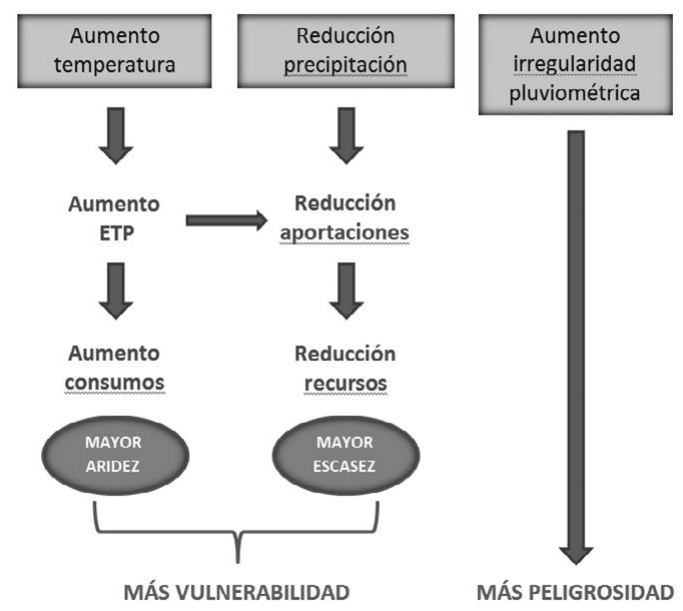

Fuente: Varias. Elaboración propia 
es necesario adoptar determinadas medidas urgentes para paliar los efectos de la escasez de agua y las sequías. El cambio climático impactará en la disponibilidad de agua dulce, pero el mayor impacto es la forma de gestionar las sequías. España es un país de una buena gestión mediante las Confederaciones Hidrográficas que junto con Portugal organiza mediante el tratado de Albufeira. Por ello, hacen faltas infraestructuras que tengan agua almacenada para utilizarla cuando no llueva.

El Informe del Panel de las Naciones Unidas para el cambio climático (IPCC de septiembre de 2013) pone de manifiesto que la diferencia entre períodos secos y húmedos se agudizará con más sequías en las zonas áridas y lluvias torrenciales en las húmedas. La disminución de las aportaciones se traducirá en la reducción de la disponibilidad hídrica. El ascenso de la temperatura se plasmará en un mayor consumo por el aumento de la ETP (agua que necesita para vivir y producir los cultivos). El aumento del consumo de agua se manifestará en una mayor aridez y vulnerabilidad que junto con la mayor irregularidad pluviométrica (sequías e inundaciones) provocará más peligrosidad (Fig. 2). El clima mediterráneo camina hacia un calentamiento, que está resultando más notorio en el interior peninsular que en la costa. Un proceso desfavorable en el régimen de los ríos y en la evaporación del agua de los embalses que generará menor producción hidroeléctrica. Y esto, afectará a la industria, ahora que el Gobierno considera la reindustrialización como objetivo prioritario del proceso de desarrollo de las regiones españolas. Proceso industrializador que debe asegurar la calidad y la eficiencia de las infraestructuras, especialmente en los ámbitos de la energía, el transporte y las telecomunicaciones.

Las consecuencias del cambio climático las sufrirán antes y de forma más intensa las regiones más deprimidas, aunque sean las que menos contribuyan a explicar esta situación. La Comisión Europea en el año 2008 consideraba que la región española más sensible al cambio climático es Extremadura de acuerdo con los impactos previsibles en relación con los escenarios de temperatura y precipitaciones. La regulación de las cuencas del Tajo y del Guadiana extremeño se han realizado en nombre de una política diferente: producción eléctrica en el Tajo, sin apenas beneficio socioeconómico para para la región pero de elevado coste social y ambiental (inundación de pueblos, desplazamiento de la población, aislamiento, etc.,) y política de regadío en el Guadiana.

En la cuenca del Tajo, la planificación hidrológica en el año 2027 se estima en una reducción del 7\% por el efecto del cambio climático. En la demarcación del Guadiana se eleva al $11 \%$. Estos valores de disminución de recursos de agua, según otros estudios, se pueden aumentar hasta el 9,5\% en el Tajo y al $13,5 \%$ en el Guadiana, el mayor de todas las cuencas peninsulares. Proceso de cambio que repercutirá en las transferencias desde las cuencas excedentarias, tanto en el establecimiento de los caudales ambientales y las condiciones de 
explotación futura como en la oposición de los sectores sociales, políticos y medio ambientales.

El Mapa de Impactos del Cambio Climático en Extremadura, sobre un conjunto de 337 estaciones pluviométricas en el año 2025, señala un descenso de $25 \mathrm{~mm}$, y de $116 \mathrm{~mm}$ para el año 2050.Persistencia de la disminución de la precipitación que se ha estimado del $57 \%$ en el año 2060 en el Guadiana ${ }^{16}$ y del $17 \%$ en el Tajo. Disminución de las aportaciones de agua que afectarán a todos los usos concretos del solar de Castilla-La Mancha, Madrid, Extremadura y Portugal que debe recibir, según el Convenio de Albufeira, en vigor desde enero de 2000: $2700 \mathrm{hm}^{3}$ por el Tajo y $600 \mathrm{hm}^{3}$ por el Guadiana en función de los recursos almacenados en los seis embalses principales extremeños, con 7247 $\mathrm{hm}^{3}$, cuando estas piezas reguladoras almacenen más de $4000 \mathrm{hm}^{3}$, el $55 \%$, que se depositará en la presa de Alqueva (Guadiana) con capacidad de $4150 \mathrm{hm}^{3}$. Dispositivo hidráulico portugués vital para el desarrollo agrario del Alentejo (transformará en regadío a 150.000 ha), el desarrollo turístico del Algarbe (abastecimiento), la producción hidroeléctrica y la lucha contra la desertificación ${ }^{17}$.

El clima mediterráneo camina hacia un aumento de la temperatura en el territorio peninsular español y hacia un descenso de las precipitaciones en las zonas interiores frente a la costa. De las estimaciones anteriores se deduce que en el ámbito de planificación del Guadiana, Castilla La Mancha (situación interior) y Extremadura (de mayor influencia atlántica), son las regiones más afectadas. La cuenca del Tajo también lo es pero en menor medida. En todo caso y si se cumplen las predicciones realizadas por el cambio climático será necesario actuar para adaptar los sectores económicos hacia la planificación de los recursos de agua para garantizar el desarrollo sostenible. Proceso de cambio climático que comporta la necesidad de conformar unas medidas de gestión integrada de cada cuenca hidrográfica como medio de adaptación para satisfacer las implicaciones de las demandas económicas (ampliación del regadío y la producción hidroeléctrica), sociales (generación de empleo) y medioambientales. Hay que evitar las prisas futuras y los sobrecostes de las obras.

La necesidad de erradicar el déficit hídrico futuro (por cambio climático) a pesar de las políticas de ahorro y gestión de la demanda, de la optimación del uso conjunto de las aguas superficiales y subterráneas, y de la máxima

16. Ayala-Carcedo, F.J. (2004). «Impacto previsible del cambio climático sobre los recursos hídricos y la sostenibilidad de la política de agua en la cuenca hispano-portuguesa del río Guadiana», en Martinez, J. Una nueva cultura del agua para el Guadiana, Fundación Nueva Cultura del Agua, Zaragoza, pag.169-178. El 30\% de los regadíos españoles del Guadiana serían completamente inviables o bien la práctica totalidad de los portugueses proyectados con Alqueva.

17. Juarez, C. (2014). Agua, Agricultura y Desarrollo Sostenible en Extremadura. Una política interna de trasvase. En Libro Jubilar en Homenaje al Profesor Antonio Gil Olcina. Universidad de Alicante.Alicante, p. 362. 
utilización de los recursos no convencionales (depuración, reutilización, etc.), sólo se puede afrontar mediante el criterio de una política de aguas asentada en el principio del reequilibrio hidráulico para compartir los recursos mediante la conexión de las cuencas hidrográfica ${ }^{18}$. El trasvase desde el Duero a la cabecera del Tajo, apoyados en las disponibilidades de excedentes reales de esta cuenca, debe llegar a la del Segura, a la cabecera del Guadiana, con mayor volumen por la previsiones del cambio climático, y aumentar las disponibilidades de Madrid, que ya presentó problemas en 1993-94 (sequía), Castilla-La Mancha y Extremadura con fines de abastecimiento, riego y medioambientales. Y es que, desde la cabecera del Tajo a Talavera de la Reina se aporta sólo el $45 \%$ de los recursos hídricos y se concentra el $85 \%$ de las demandas. Por ello, en el tramo Aranjuez-Toledo - Talavera de la Reina las condiciones ambientales dejan mucho que desear por las condiciones ecológicas y la baja calidad del agua con clara afectación a la provincia de Cáceres. Un proceso que se acrecienta por la pequeña capacidad de respuesta al Convenio de Albufeira, que ahora soportan los embalses de Valdecañas, Gabriel y Galán y Rosarito sin que lleguen los caudales comprometidos de Aranjuez, Toledo y Talavera de la Reina.

El desarrollo sostenible del medio rural extremeño pasa por cultivar una parte de su espacio productivo agrario para no depender de las importaciones de alimentos y mejorar su competitividad en el mercado globalizado. Pero, si no se dispone de agua, no se podrán prever actuaciones en el medio rural ni establecer negocios. En el período seco de 1993, con absoluta falta de reserva de agua almacenada en los embalses de la cuenca del Guadiana, no se pudo regar: «Solamente los regadíos del norte de la provincia de Cáceres pudieron utilizarse como tales, trasladando a estas comarcas una parte importante de la producción extremeña del tomate para industria, que junto con la habitual del tabaco, convirtió a la provincia de Cáceres, gracias a los recursos de agua, y por vez primera en su historia, en el mayor contribuyente a la Producción Final Agrícola de Extremadura, que Badajoz ${ }^{19}$.

Siempre he considerado, por mi vinculación y relación con las cuencas del Guadiana, Tajo y tramo final del Duero, que un trasvase de la cuenca del Duero no sería cuestionado por las autoridades portuguesas debido a que si este colector vería disminuido su caudal, al Gobierno lusitano le interesa más que se aumenten y garanticen los del Tajo y, sobre todo, los del Guadiana (Alqueva). La realización de un posible trasvase del Tajo al Guadiana, sólo por el territorio extremeño (trasvase interno), desde el embalse de Valdecañas (Tajo) por las

18. Juarez, C. (1994). Intercomunicación de cuencas. Recursos compartidos. Seminario Iberoamericano sobre: Derecho y Tecnología del Agua.-Instituto Universitario del Agua y las Ciencias Ambientales. Alicante. Mecanografiado.

19. Muslera, E. y Pulido, F. (1997): «El sector agrario extremeño», Situación (Serie de Estudios regionales de Extremadura), pp. 91-109. 
comarcas cacereñas de los Ibores y Las Villuercas (río Guadalupejo, plataforma de ensamblaje geográfico e histórico con la mal llamada La Siberia) hasta el embalse de García de Sola (Guadiana), significaría un paso adelante, decisivo y valioso de la planificación hidrológica y de la racionalidad económica y social más completa.

La realización de este trasvase pretende crear más región y aumentar las posibilidades de desarrollo agrario, industrial y de servicios (turístico). Una respuesta adecuada a las previsiones de cambio climático necesitada de solución para no condicionar el desarrollo sostenible de los territorios de previsible mayor afectación. Extremadura tiene que seguir apostando por la ampliación de la superficie de regadío porque fija población e implanta agroindustria que es una fuente de riqueza. Consideramos que en la asignación de recursos no deben primar criterios de mercado sino sociales y de uso del territorio. El mayor impacto de éxodo rural lo han sufrido los municipios de secano. El cambio climático y la previsible disminución de caudales tienen que dejar de ser un problema de futuro para el desarrollo sostenible de las regiones. La sociedad, los técnicos y los políticos deben resolver favorablemente las necesidades de riqueza y bienestar para las generaciones actuales sin afectar a la demanda futura.

LA PRODUCCIÓN HIDROELÉCTRICA COMO FACTOR DE DESEQUILIBRIO ECONÓMICO TERRITORIAL

\section{Infraestructura hidroeléctrica y desigualdad económica provincial/regional}

El desarrollo industrial se fundamenta en el uso creciente de las fuentes de energía. El consumo eléctrico por habitante es considerado como el mejor indicador del nivel de desarrollo de la sociedad. Las centrales hidroeléctricas se han emplazado en las zonas susceptibles de ser mejor aprovechadas para la producción que de promover el desarrollo económico del territorio.

El agua es poder energético y económico. La energía hidroeléctrica es la de mejor y más brillante calidad de las renovables. El aprovechamiento de los cursos fluviales para uso industrial goza de larga tradición en nuestro país. En 1902 se confirma que el 40\% de las instalaciones generadoras eran de aprovechamiento hidráulico. Las inversiones en agua han sido el catalizador para el crecimiento económico (regadío, energía), la creación de empleo y una mayor movilidad social. Hay que lograr crear un sistema que permita una visión global del agua como factor estratégico para un desarrollo económico y social armónico del conjunto de la sociedad española.

La aplicación del agua a la agricultura no es la única actividad económica que produce beneficios. Por tanto, no se podía pensar sólo en la ampliación del espacio regado conociendo el incremento de renta que el aprovechamiento 
hidroeléctrico genera. Sin embargo, la Ley de Aguas de 1879, marco jurídico donde se establece el orden de prelación de los aprovechamientos, relegaba a los usos industriales del agua al quinto lugar, en relación con la situación económica de país ( $80 \%$ de la población activa pertenecía al sector primario).

Las nuevas necesidades no tomadas en consideración (energía eléctrica para alumbrado y el incipiente desarrollo industrial) han determinado que, en materia de aprovechamiento, se haya dictado el mayor número de disposiciones reguladoras favorables al uso hidroeléctrico, que explican la construcción de grandes embalses con finalidad estrictamente hidroeléctrica. Un proceso que no fue previsto por el pensamiento regeneracionista pero que ha conformado una verdadera política energética que en casi nada ha beneficiado a las provincias/ regiones donde están ubicado los mayores embalses hidroeléctricos: Cáceres, Salamanca, Guadalajara, Orense, Zamora etc. ${ }^{20}$ donde confluyen la abundancia de agua y desniveles topográficos.

El Estado no hizo por sí mismo la construcción de presas y embalses para uso hidroeléctrico aunque si ha contribuido con subvenciones desde la Ley Gasset de 1911 y durante la Dictadura de Primo de Rivera de 1923-1931. Por ello, desde la declaración de suministro eléctrico como servicio público en 1924 las compañías privadas presumían de haber acometido por sí solas, sin apoyo de la Administración, inversiones colosales en la construcción de embalses exclusivos para la producción hidroeléctrica ${ }^{21}$. Las disposiciones favorables al aprovechamiento hidroeléctrico justifican la construcción de grandes embalses con finalidad estrictamente hidrológica. Y es que, el uso hidroeléctrico no consume agua y es compatible con otros aprovechamientos consuntivos (riego), lo que conceptualmente aparece bajo el término de aprovechamiento múltiple. Un proceso que ha variado del $38 \%$ en los años setenta al 50\% en 1989 para uso múltiple, los de mejor futuro por la explotación integral del recurso.

El Plan Nacional de Obras Hidráulicas de 1933, que no se llegó a aprobar, señalaba la necesidad de un verdadero plan conjunto de la política hidráulica estatal. Se imponía la gestión estatal del recurso agua para favorecer tanto a la producción hidroeléctrica, que estaba en manos de la iniciativa privada, como a la expansión de los regadíos. Aprovechamiento integral del agua contemplado en el Plan que no causó efecto por falta de realización. Sin embargo, esta conjunción de aprovechamientos energéticos y consuntivos (agua consumida para regadío) que ya se contemplaba en el Plan de 1933, no quedó debidamente recogida en el Plan de Peña Boeuf de 1940, tal vez por reacción a una etapa

20. JuÁrez, C. (1998). Agua y regadío en España. Etapas, op. cit. 39.

21. Bartolome, J. (2011) ¿Fue el sector eléctrico un gran beneficiario de la Política Hidráulica anterior a la Guerra Civil? (1911-1936). Hispania. Revisa Española de Historia, n. ${ }^{\circ}$ LXX 239 (septiembre-diciembre), pp.789-818. 
política diferente ya que la planificación hidrológica incluida en este Plan está fundamentada en el de 1933, que no se aprobó.

Y es que, el Pan de 1940 se limitaba a señalar: «En un primer momento pensamos hacer un estudio conjunto de los aprovechamientos hidroeléctricos; pero el hecho, fundamental para nosotros, de instalación de riegos hace que esos aprovechamientos industriales tengan una desvalorización, debido a la irregularidad de producción de energía, que sólo puede salvarse por coordinación con otros saltos industriales de un modo acertado «. Expresión «saltos industriales «que no formaban parte del Plan General pero donde se incluían un número muy considerable de embalses que dependían de la iniciativa privada. Y fueron estos los que dieron lugar a la explosión de pantanos, entre 1954 y 1970, período álgido durante el cual se sextuplica la capacidad de los embalses peninsulares ${ }^{22}$.

No obstante, durante este tiempo el Estado construyó un número considerable de presas (Plan Badajoz, Jaén y de la Tierra de Campos etc.) y terminó otras iniciadas en etapas anteriores ${ }^{23}$. La necesidad de construir tales embalses en la cuenca del Guadiana para regadío y la idea de un total aprovechamiento, determinó utilizar también, en la salida del agua de estas presas, diferentes centrales hidroeléctricas. Los embalses de Cijara, García de Sola (Puerto Peña) y Orellana la utilizan para aprovechamiento hidroeléctrico en cada uno de ellos, antes de que la misma riegue las 105.000 has del Plan Badajoz. Un modelo que se repite en el Plan Jaén de 1953 con el embalse del Tranco como sostenimiento del regadío y producción hidroeléctrica sin apenas repercusión económica y social en la Sierra de Segura. Construcción de presas con la doble finalidad de riegos y energía, que ya se habían plasmado en los embalses de Camarasa y Tremp en el Noguera Pallaresa entre 1916-1922. Pero, sin duda, el papel estelar correspondió a los embalses hidroeléctricos. Período álgido de la década de los $60 \mathrm{y}$ primera mitad de los 70 que registraron una tasa media de crecimiento del $10 \%$ anual acumulativo, lo que suponía cerca de cuatro veces más de producción frente a la etapa anterior.

Desde 1910 hasta 1960, el agua constituyó el principal recurso para la obtención de electricidad en España. El despegue industrial iniciado a partir de $1910 \mathrm{y}$ el abastecimiento de las ciudades fue suministrado por las centrales hidroeléctricas que se vio truncado por los efectos de la crisis mundial de 1929,

22. TORRENT, L. «Los aprovechamientos hidroeléctricos en los planes hidrológicos» op. cit. pp.5. También: Espejo, C y García, R (2010) «Agua y Energía: Producción hidroeléctrica en España». Investigaciones Geográficas n. ${ }^{\circ}$ 51, pp. 107-129.

23. JuAREZ, C. (1974). Evolución de la energía eléctrica en la provincia de Badajoz». Revista de Estudios Extremeños, mayo-agosto pp. 363-382. Gallego, V. J (2012). El Plan Jaén de 1953 y sus antecedentes. Una oportunidad perdida para el desarrollo de la provincia de Jaén en el siglo xx. Universidad de Jaén. Jaén 434 pp. PEÑA,M. (1973).-El Plan de la Tierra de Campos y su realización». Estudios Geográficos n. ${ }^{\circ}$ 130, pp. 170-185. 
por el proceso bélico de 1936-39 y la vocación agrarista del franquismo derivada de la autarquía impuesta por el aislamiento internacional. El Estado asumió la dirección de la economía hasta los nuevos horizontes del Plan de Estabilización de 1959 y los Planes de Desarrollo Económico y Social de 1964-1975 que sustituían al agrarismo por la industrialización y el fomento del turismo.

La industria hidroeléctrica ha de emplazarse en los lugares de propicias condiciones físicas, desde los cuales puede luego transportarse al mercado que la reclamó. Las instalaciones se agrupan en España «según dos triángulos con vértices conjunto en Vizcaya y que se abren, opuestos entre sí, uno hacia el Mediterráneo y otro hacia el Atlántico. Aquél, apoya su lado septentrional en los mismos Pirineos y pone su base en una línea que se extiende paralela al mar latino, desde la provincia de Gerona hasta el bajo Ebro. El otro se abre en sentido contrario, con su lado Norte en la rasa cantábrica, para colocar su base en otra línea trazada desde el Norte de Galicia hasta los Arribes del Duero» ${ }^{24}$. Los restantes complejos hidroeléctricos de importancia que se hallan fuera de esta zona, se limitan a lugares donde las más diversas condiciones climáticas y de caudal se ven compensadas por las topográficas o geológicas.

En el caso del Tajo, su instalación se debe tanto en la cabecera: embalses de Entrepeñas y Buendía (Guadalajara y Cuenca), como en el tramo final de la provincia (Cáceres): Alcántara, Cedillo, Valdecañas y Gabriel y Galán (Alagón), a su mayor caudal y características geológicas lo que explica la magnitud de los embalses, de los saltos y la elevada cuantía de la potencia instalada. Las aguas reguladas en el alto Tajo cumplen una doble finalidad. Por un lado, alimenta tanto a cinco centrales hidroeléctricas y la desaparecida central nuclear de «José Cabrera» como permite a sus caudales, excedentes y regulados, ser transferidos a la cuenca del Segura (Trasvase Tajo-Segura), a lo que no se opusieron las empresas hidroeléctricas. Su no comparecencia a la información pública deriva de la serie de compensaciones obtenidas de la Administración como: la adquisición a bajo precio de la energía reservada al Estado en los saltos del Tajo, Júcar y Segura y la concesión de un equivalente energético, $0,79 \mathrm{Kw} / \mathrm{h}$., por cada metro cúbico extraído de la cuenca del Tajo, mediante el salto reversible de Bolarque (consume $0,87 \mathrm{Kw} / \mathrm{h}$ y produce $0,58 \mathrm{Kw} / \mathrm{h}$ punta) y la serie de aprovechamientos en el canal del Trasvase ${ }^{25}$. En el tramo final del Tajo se ha montado el mayor embalse de interés hidroeléctrico de España: Alcántara con capacidad de 3160 $\mathrm{hm}^{3}$, Valdecañas en el sexto lugar y Gabriel y Galán en el noveno.

24. Cabo, Alonso, A. (1960). «Factores geográficos de la industria eléctrica española». Geográphica. Año VII. Enero-Diciembre, p. 37.

25. Juarez, C. (1991). «Planificación hidrológica y desarrollo económico: El Trasvase TajoSegura, op. cit. p. 40. 
Si de las capacidades de almacenamiento deducimos los embalses puramente hidroeléctricos, el promedio nacional al principio de los años noventa era de $63 \mathrm{l} / \mathrm{m}^{2}$ y la provincia de Badajoz, después de entrar en funcionamiento el embalse de La Serena, el mayor de España con $3219 \mathrm{hm}^{3}$, y el pantano de Alange con $852 \mathrm{hm}^{3}$, ocupa el primer lugar con $289 \mathrm{l} / \mathrm{m}^{2}$ seguida de Guadalajara con $2301 / \mathrm{m}^{2}$, Cáceres con 214 1/ $\mathrm{m}^{2}$, Córdoba, Madrid, Jaén, Cuenca (cuadro n. ${ }^{\circ}$ ). Guadalajara, con los embalses de la cabecera del Tajo y Cuenca, con Alarcón y Contreras, regulando el Júcar, son las provincias más generosas al entregar, sin apenas utilizarlas, las aguas embalsadas en sus territorios. Capacidad de generar energía hidroeléctrica que hizo ocupar, en 1949, a la cuenca del Júcar el primer lugar de producción con el 31,9 \%, seguida del Ebro con el 25,9\% y el Duero con el 16,9\%. Balances territoriales que a lo largo del tiempo han ido cargando la producción hidroeléctrica a las provincias más atrasadas en beneficio de la industrialización de las regiones más desarrolladas.

El uso del agua para producir energía es la tercera gran necesidad después del abastecimiento y el aprovechamiento agrario. El sector hidroeléctrico en España comienza en 1885. La primera central hidroeléctrica se pone en marcha en 1890 en Andoain (Guipúzcoa), al coincidir en un mismo lugar un salto de agua y un centro de consumo ${ }^{26}$. La irrupción de la electricidad cambia por completo los factores de localización. La creciente industrialización provoca una gran demanda de energía que es suplida por la hidroelectricidad. Durante el período de 1914-1939 comienza el desarrollo de la energía hidroeléctrica con la construcción de las primeras grandes presas: Ricobayo (Zamora) en el río Esla, con capacidad de $1200 \mathrm{hm}^{3}$. La central se pone en servicio en 1935 para el abastecimiento de Bilbao y su industria metalúrgica. Fue el inicio del aprovechamiento de la cuenca del Duero. Modelo de progreso que Indalecio Prieto quiso trasladar a las orillas del Guadiana (Cijara, precedente del Plan Badajoz) como el medio más eficaz para mejorar la situación económica y social del territorio.

En 1950 se inicia el despegue industrial que se acreciente en los años sesenta por las mejoras tecnológicas más productivas, posibilitadas por el suministro regular y barato de la energía eléctrica. La regulación casi absoluta de los cauces de agua aprovechables se orientaba hacia la producción hidroeléctrica y hacia el negocio privado, poniendo fin a los ideales de desarrollo regional y equilibrio territorial que inspiraron los planes agrarios, tanto los regeneracionista como los de la segunda república y el primer franquismo. La energía hidroeléctrica en España ha sido siempre creciente aunque la participación en el total eléctrico producido ha ido disminuyendo desde el $93 \%$ en 1940 al 8,1\% en el 2008. Porcentaje que en el 2014 se eleva al 15,5\%.

26. Ferrer, M. (1968). La industria en la España Cantábrica. Ed. Moretón. Bilbao p. 22. 
Cuadro 3. Volumen total de embalses, excluidos los hidroeléctricos

\begin{tabular}{|c|c|c|c|}
\hline \multicolumn{2}{|c|}{$\begin{array}{c}\text { Volumen total de embalses en relación con la } \\
\text { superficie provincial }\left(1 / \mathrm{m}^{2}\right)\end{array}$} & $\begin{array}{r}\text { Volumen de embalses, excluidos los } \\
\text { hidroeléctricos, en relación con la superficie } \\
\text { de cada provincia }\left(1 / \mathrm{m}^{2}\right)\end{array}$ \\
\hline Cáceres & 387 & Badajoz & 289 \\
\hline Badajoz & 289 & Guadalajara & 230 \\
\hline Salamanca & 280 & Cáceres & 214 \\
\hline Guadalajara & 231 & Córdoba & 154 \\
\hline Orense & 225 & Madrid & 134 \\
\hline Guipúzcoa & 6 & Vizcaya & 4 \\
\hline Burgos & 5 & Valladolid & 1 \\
\hline Vizcaya & 4 & Orense & 0 \\
\hline Valladolid & 1 & Zamora & 0 \\
\hline
\end{tabular}

Fuente: Ministerio de Obras Públicas. Elaboración propia.

Hacia 1960, en las tierras unamunianas de la penillanura salmantina -zamorana, la hidráulica era la parte más viable del proceso de modernización. También de la tecnología transformadora más radical. Una realidad sicogeográfica que compartimos los geógrafos y los poetas salmantinos que acuñaron el término de electro-franquismo (Fernando R. de la Flor). Terminología bajo la cual se encierra la idea del acelerado programa de construcción de embalses destinados a producir electricidad iniciado a mediados del siglo Xx en la cuenca del Duero: Saucelle (1956), Aldeadávila (1962), la mayor central hidroeléctrica de España, y Almendra-Villarino (1970 ${ }^{27}$ la tercera, después del embalse de Alcántara (Cáceres). La disponibilidad de agua se convierte en factor estratégico de la economía de la provincia y la región (Cuadro n. $\left.{ }^{\circ} 4\right)$.

Las centrales hidráulicas gozan de mayor flexibilidad en la producción eléctrica que las nucleares y las térmicas. Este valor adicional la convierte en un complemento indispensable para regular y cubrir los picos de la demanda (horas punta) y generar mayor beneficio económico a los productores. Por ello, la mayor disponibilidad de energía hidroeléctrica y su garantía favorece a las empresas productoras por ser la forma más barata de generar electricidad y al final cobrar el precio más alto. Invertir en agua,» beneficios caídos del cielo»

27. GARCIA ZARZA, E. (1973). El aprovechamiento hidroeléctrico salmantino-zamorano. Universidad de Salamanca. Salamanca, 1973. 73 pp. 
Cuadro 4. Efectos económicos de las sequías sobre la producción hidroeléctrica en la cuenca del Duero

\begin{tabular}{|l|c|c|c|c|c|c|}
\hline & \multicolumn{2}{|c|}{ AÑO SECO } & \multicolumn{2}{c|}{ AÑO MEDIO } & \multicolumn{2}{c|}{ AÑO HÚMEDO } \\
\hline Producción $(\mathrm{GWh})$ & $2.975,0$ & $49 \%$ & $6.040,0$ & $100 \%$ & $10.486,5$ & $174 \%$ \\
\hline Bombeo $(\mathrm{GWh})$ & 938,1 & $180 \%$ & 522,0 & $100 \%$ & 451,9 & $87 \%$ \\
\hline roducción total $(\mathrm{GWh})$ & $\mathbf{3 . 6 3 1 , 7}$ & $\mathbf{5 6 , 7 \%}$ & $\mathbf{6 . 4 0 5 , 4}$ & $\mathbf{1 0 0 \%}$ & $\mathbf{1 0 . 8 0 2 , 8}$ & $\mathbf{1 6 9 \%}$ \\
\hline
\end{tabular}

Se ha considerado un rendimiento medio del 0,7 para la producción debida al bombeo.

Fuente: Plan Especial de Actuación. Confederación Hidrográfica del Duero.

Cuadro 5. Ingresos y costes de producción hidroeléctrica

\begin{tabular}{|l|c|c|c|}
\hline & SECO & MEDIO & HÚMEDO \\
\hline Ingresos producción (millones de $€$ ) & 290 & 448 & 648 \\
\hline Coste bombeo (millones de $€$ ) & 37 & 20 & 16 \\
\hline Diferencia & $\mathbf{2 5 3}$ & $\mathbf{4 2 8}$ & $\mathbf{6 3 2}$ \\
\hline
\end{tabular}

Fuente: Plan Especial de Actuación. Confederación Hidrográfica del Duero.

(del inglés, windfall profits), siempre es un negocio por su alta rentabilidad. El gran negocio privado con el agua de todos ${ }^{28}$

La cuenca del Duero dispone de excedentes de caudales hídricos. Mucho de los embalses tienen aprovechamiento energético y se levantaron como en Cáceres, Salamanca, León, Zamora y otras provincias, con escaso miramiento hacia los pueblos que inundaron ${ }^{29}$.La población que no ha emigrado, después de su construcción y puesta en funcionamiento, ha convivido junto a estos reservorios sin disponer, en algunos casos, de enganches de luz ni de agua. La intensa explotación hidroeléctrica en las provincias de Cáceres, Salamanca, Zamora, Orense, Guadalajara etc, no ha contribuido de forma clara y determinante en la mejora económica y social de los territorios afectados ni de los pueblos que soportan a los pantanos y su área de influencia. Modelo de desarrollo que ha provocado emigración y pérdida de capacidad productiva de las comarcas que

28. Mendez, R. (2010). «El gran negocio con el agua de todos».-El País 10 /9/2010.- Las eléctricas pagan menos de 20 millones al Gobierno por el caudal de los ríos, con el que ganan 1000 millones.

29. Llamazares, J. (2015). «Distintas maneras de mirar al agua» El País 14/02 /2015. Riaño (León) fue el pantano que Iberdrola exigió a cambio de cerrar la central nuclear de Lemoniz (Vizcaya). El destierro olvidado de los vecinos de los pueblos sumergidos en el pantano del Porma (León). 
acogen a los embalses ${ }^{30}$. El gran beneficiado de la política hidráulica es el sector eléctrico en mano de empresas de naturaleza privada. La hidroelectricidad es otra forma de apropiación de los recursos hídricos de las regiones deprimidas. Hacer accesible las riquezas hidráulicas de un territorio puede enriquecer considerablemente la vida de sus habitantes ${ }^{31}$.

Desde 1940 a 1973 (excepto 1970 por sequía) la producción hidroeléctrica ha contribuido con más del $50 \%$ de la energía consumida en España. En los años húmedos se supera la producción en 45.000 gigavatios por hora; en los años secos no llega a 25.000. La media es de $31.000 \mathrm{GWh} /$ año, sólo superada por Francia e Italia dentro de la Unión Europea. En la cuenca del Duero la producción entre los años húmedos, medios y secos (Cuadros n. ${ }^{\circ} 4$ y 5) pone de manifiesto las grandes diferencias de disponibilidad de caudales que se acrecienta con las de precios y las necesidades del sistema eléctrico. La disminución de la producción hidroeléctrica, provocada por las sequías, no sólo perjudica a las compañías propietarias de los saltos sino a los ayuntamientos que tienen este tipo de centrales en sus términos municipales al ver reducido sus ingresos por el canon que reciben en función de la energía generada cada año

En el período 1966-1975 (Cuadro n. ${ }^{\circ}$ 6) la provincia de Cáceres exportó el 91\% de la producción de origen hidráulico ocupando el cuarto lugar después de Salamanca, Orense y Lérida. Estas provincias no recibieron compensación alguna. Tampoco ninguna de las diferentes regiones productoras. Estas y otras provincias constituyen las llamadas «Bolsas de Pobreza» las cuales, a pesar de haber perdido buena parte de su población por la emigración, ocupan los últimos lugares de «renta per cápita» en el conjunto nacional. En cambio, las cinco provincias con mayor «renta per cápita»: Vizcaya, Madrid, Guipúzcoa, Álava y Barcelona fueron las grandes beneficiadas del sistema eléctrico español al disponer de energía eléctrica al mismo precio que las zonas productoras, sin apenas aportación eléctrica.

En 1975 la provincia de Cáceres ocupaba el último lugar (50) en la «renta per cápita»; Orense la 45 y Zamora la 39. En consecuencia, las provincias que obtienen los mayores niveles de ingresos y consumen la mayor parte de la energía hidroeléctrica son las que menos aportan. Resulta ingenuo creer que los territorios de menor disponibilidad económica (provincias deprimidas) puedan cambiar su dinámica de desarrollo sostenible mediante la ampliación continuada y paralela de aumento eléctrico (nucleares: Cáceres, Guadalajara) y exportación

30. GARCIA ZARZA, E. (1990). «La producción hidroeléctrica cacereña. Impacto socioeconómico». Estudios de Geografía. Homenaje a J.L. Cruz Reyes. Universidad de Salamanca. Salamanca. pp. 105-131.

31. NAREDO, J M. (1978). «La hidroelectricidad: otra forma de apropiación de los recursos naturales extremeños». En GaVIRIA, M, NAREdo, J.M. et alli. Extremadura Saqueada. Ruedo Ibérico. Paris-Barcelona, p. 73. 
Cuadro 6. Balance energético medio anual del decenio 1966-75

\begin{tabular}{|l|c|c|c|c|c|c|c|}
\hline & \multicolumn{2}{|c|}{ PRODUCCIÓN (en millones de kw/h) } & \multicolumn{2}{c|}{ CONSUMO } & SALDO \\
\cline { 2 - 9 } & Hidráulica & Térmica & TOTAL & $\begin{array}{c}\text { \% sobre } \\
\text { el total } \\
\text { nacional }\end{array}$ & $\begin{array}{c}\text { Millones } \\
\text { de kw/h }\end{array}$ & $\begin{array}{c}\text { \% sobre } \\
\text { el total } \\
\text { nacional }\end{array}$ & $\begin{array}{c}\text { (millones } \\
\text { de kw/h) }\end{array}$ \\
\hline Vizcaya & 169,6 & $1.840,1$ & $2.009,7$ & 3,35 & $3.551,1$ & 7,10 & $1.503,4$ \\
\hline Madrid & 155,9 & 4,3 & 160,2 & 0,27 & $5.204,3$ & 10,52 & $5.144,1$ \\
\hline Guipúzcoa & 70,0 & 966,2 & $1.036,3$ & 1,73 & $2.423,3$ & 4,90 & $1.394,4$ \\
\hline Álava & 128,9 & 3,6 & 132,6 & 0,22 & 842,3 & 1,70 & 709,7 \\
\hline Barcelona & 187,5 & $3.347,7$ & $3.534,7$ & 5,90 & $6.926,1$ & 14,00 & $3.391,3$ \\
\hline $\begin{array}{l}\text { Media de las cinco } \\
\text { primeras provincias } \\
\text { en renta per cápita }\end{array}$ & 712,1 & $6.161,5$ & $6.873,6$ & 11,47 & $18.907,5$ & 38,22 & $12.033,8$ \\
\hline Castilla y León & $7.676,0$ & $5.225,3$ & $12.901,2$ & 21,52 & $5.042,3$ & 10,23 & $7.858,9$ \\
\hline Andalucía & 973,3 & $4.571,3$ & $5.544,6$ & 10,24 & $5.023,7$ & 10,16 & 520,0 \\
\hline Galicia & $5.483,8$ & 382,4 & $5.866,1$ & 9,90 & $2.980,9$ & 8,02 & $2.885,2$ \\
\hline Aragón y Lérida & $6.450,9$ & $1.670,8$ & $8.121,7$ & 13,56 & $2.825,9$ & 5,72 & $5.295,7$ \\
\hline Extremadura & $2.139,5$ & - & $2.139,5$ & 3,56 & 441,4 & 0,90 & $1.698,2$ \\
\hline Cáceres & 1837,0 & - & 1837,0 & 3,06 & 166,4 & 0,34 & $1.670,6$ \\
\hline Badajoz & 302,5 & - & 302,5 & 0,50 & 275,0 & 0,56 & 27,6 \\
\hline
\end{tabular}

Fuente: Ministerio de Industria. Extremadura Saqueada.

de energía. Se confirma, por tanto, las profundas desigualdades de nivel de renta entre los territorios que producen la energía y los que la consumen. Un modelo de progreso necesitado de cambio porque la «generación de energía eléctrica afecta de forma negativa al entorno y conlleva importantes costos ambientales que repercuten sobre los territorios donde se instalan las centrales, poniendo en peligro un posible desarrollo sostenible $»^{32}$.

\section{El canon energético como aportación para el desarrollo local y provincial}

La crisis económica de 1975-1985 cambió la noción de desarrollo económico. El nuevo concepto pasa por ser el resultado del esfuerzo de una sociedad y el espacio que ella organiza. El desarrollo territorial significa la utilización de los recursos económicos de una provincia /región por sus residentes para mejorar la condición económica y generación de empleo. La energía hidroeléctrica que se ha producido en varias provincias y consumido en lugares diferentes no ha reportado ningún beneficio económico a los territorios productores durante el

32. Zotes, Y.N. y Doldan, X.R. «El sector eléctrico español. La producción hidroeléctrica como causa de la desigualdad entre los distintos territorios del Estado español». Congreso de la Asociación Española de Ciencia Regional. XXX Reunión de Estudios Regionales. 
período, 1940-1981. Estos espacios provinciales están soportando una gran contaminación e impacto ambiental del que están liberados los territorios consumidores y no productores. Como el precio de la electricidad es igual para todo el Estado, las áreas productoras no están compensadas por la contaminación del aire y por el impacto ambiental y paisajístico de las centrales hidráulicas, nucleares, térmicas etc. Se imponía la necesidad de aplicar un impuesto por el impacto ambiental de la producción hidroeléctrica y su transporte. Este impuesto energético $(0,17$ pts. Kw) permitiría disponer de recursos económicos para diseñar un ordenamiento planificado y potenciar el desarrollo agrario, industrial y de los servicios, especialmente turístico, de las zonas productoras.

Los pueblos tienen derecho a obtener una compensación económica por la explotación de sus recursos y los beneficios de las rentas que percibe el Estado. La energía que se producía en las provincias exportadoras no representaba ningún beneficio económico a su población. Las regiones más deprimidas, donde se concentra el agua embalsada y la producción hidroeléctrica, que debían haberse beneficiado de los efectos favorables de los regadíos, vieron relegados sus intereses en favor de las regiones más desarrollada, hacia donde se ha encauzado la energía hidroeléctrica producida y, con ella los beneficios económicos y sociales. Plasmación de una verdadera política energética que en nada ha beneficiado a las regiones donde están ubicados los principales embalses: Castilla y León (Duero), Galicia (sistema Miño-Sil), Extremadura (Tajo-Guadiana y nucleares) y Aragón (ríos pirenaicos). Se ha condenado a estas regiones al subdesarrollo y a la emigración.

La necesidad de modificar esta situación de desigualdad económica determina la implantación del canon energético como compensación necesaria (menor demanda de petróleo porque cada Kwh producido evita la importación de 220 gramos de este producto), justa (menor coste de producción de energía) y solidaria (mejor distribución de la riqueza entre las regiones), regulada por la Ley 7/1981 de 25 de marzo, sobre producción de energía eléctrica ${ }^{33}$. Las remesas económicas recibidas por su capacidad de producción y potencia instalada se invertirían en beneficio del desarrollo de las zonas directamente afectadas por la ubicación de las instalaciones generadoras de energía eléctrica. Lo contrario implicaría una subvención de los territorios deprimidos y exportadores de energía, a las provincias industriales de mayor renta por habitante. Sería una tasa medioambiental por el impacto que genera la producción de energía. De todas formas, el mayor problema era la propia calificación del canon. No se sabía si el canon era un estímulo a la implantación de determinados tipos de centrales generadoras, una indemnización por las servidumbres creadas por las

33. Hervella, J. (1981). «El canon energético, compensación necesaria, justa y solidaria». Diario ABC, 3/09/1981, p. 128. 
infraestructuras eléctricas, o una medida de política regional sucedánea de una discriminación tarifaria ${ }^{34}$. Una fuente de ingresos para las haciendas de las provincias que llega sin ninguna planificación previa.

Las transferencias hídricas trasvasan junto con el agua desarrollo, poder económico (provincias generadoras de electricidad frente a las consumidoras), y consiguientemente poder político. Proceso que genera un modelo de articulación territorial más desigual y menos equilibrado y solidario aun que el que tenemos. El canon debe estar orientado hacia la población que soporta los embalses para que se puedan beneficiar del efecto económico de la producción. El valor monetario recaudado se entregaba proporcionalmente a su capacidad de producción y potencia instalada de energía hidroeléctrica, nuclear o de carbón. Su aplicación y distribución hasta el ingreso de España en la Unión Europea en 1986 no consiguió cambiar la dinámica económica y demográfica de las zonas/ provincias directamente afectadas por la implantación de las instalaciones. Además, antes de pagar este impuesto se procedió a una subida de las tarifas, en parte con este fin, por lo que las propias zonas productoras tuvieron que pagar parte del impuesto ${ }^{35}$.

El canon como factor compensatorio de las desigualdades entre los diferentes territorios ha sido tardío en el tiempo de aplicación, escaso y no ha solucionado el problema de desequilibrio económico y generación de empleo entre las regiones productoras y consumidoras de energía. El efecto ha sido pequeño. Entregado a las Diputaciones Provinciales no se ha hecho el mejor uso aunque ha servido para mejorar la infraestructura del medio rural sin reducir la emigración y la pérdida de capacidad productiva de los territorios afectados. Los pueblos tienen derecho a obtener una retribución del Estado por la explotación de sus recursos mediante una renta al existir una relación desigual entre la localización de los recursos, su afectación medioambiental, las rentas que producen y la pobreza de la sociedad necesitada de cambio.

El canon energético correspondiente al segundo semestre de 1982, primero del que tenemos información, se distribuye en la forma siguiente: Cáceres, 494,2 millones de pesetas; Asturias, 317, 4; La Coruña,296,5; Salamanca265, 6; Zamora, 257,4 etc. La provincia que menos dinero recibe por este concepto es Alicante con 94.381 pesetas, y algo más Valladolid con 0,7 millones de pesetas. En 1986 se produce su derogación debido a la introducción del IVA. Se crea el Fondo de Compensación Territorial que en poco ha beneficiado a las provincias más productoras de energía. En este tiempo el Gobierno desoye el pago de 36 millones de euros por la supresión del canon energético a la provincia de

34. EYSER. Estudio de reconocimiento territorial de Castilla-León. 1981. Avance, pág. 275. 35. GARCIA ZARZA, E. (1990) «La producción hidroeléctrica cacereña....op. citada, p. 129. 
Cáceres, la de mayor producción de eléctrica ${ }^{36}$. La provincia extremeña acoge la mayor potencia eléctrica instalada: 3992 megawatios (siete aprovechamientos hidroeléctricos en el Tajo y la central nuclear de Almaraz $)^{37}$. La provincia de Tarragona, Asturias, La Coruña y hasta 11 provincias afectadas debían recibir la dotación inicial de 390,6 millones de euros. Canon energético malo, necesitado de actualización y cambio porque tiene que estar orientado y focalizado hacia la población que soporta los embalses y las centrales nucleares.

El análisis de estos datos pone de manifiesto la gran desigualdad de los diferentes territorios y su consumo. Un desequilibrio permanente que se hace más significativo cuando relacionamos la producción eléctrica con el consumo de cada una de las unidades territoriales. Energía que convertía a Castilla y León, en los albores del siglo xxI, la región más excedentaria seguida de Extremadura, Asturias y Galicia. En cambio Barcelona, Madrid, Vizcaya, las de mayores valores de renta, ocupaban los primeros lugares en el consumo neto por provincia. Un modelo energético necesitado de cambio y de compensación económica.

La energía hidroeléctrica, como se analiza en esta aportación, goza de larga tradición en España y es de las que menor impacto medioambiental produce. La política estatal ha paralizado el dinamismo de la vida económica de las provincias menos desarrolladas y exportadoras de energía eléctrica introduciendo privilegios de aprovechamientos para los territorios más desarrollados con el agua de todos. Empobrecimiento sistemático de las provincias más deprimidas económicamente que ha ampliado la desigualdad y la fractura social.

La Ley 15/2012 de medidas fiscales para la sostenibilidad energética de 27 de diciembre creó un nuevo canon por la utilización de bienes de dominio público hidráulico denominado comúnmente canon hidroeléctrico, que incorporó como artículo 112 bis en el Texto de Reforma de la Ley de Aguas. El objetivo es establecer una tasa destinada a la protección y mejora del dominio público hidráulico a través de las Confederaciones Hidrográficas. Sin embargo, el proyecto de real decreto modifica, la primera propuesta por la cual el canon no se aplicará a todas las cuencas hidrográficas, sino a las intracomunitarias, sobre las que el Estado tiene competencia mientras están liberados los ríos que discurren por una sola comunidad. Esto permite a las diferentes Comunidades Autónomas quedarse con lo recaudado. Nuevo marco legal que todavía no se ha aplicado por las trabas que ha encontrado en su desarrollo. Entendemos que es el momento oportuno de establecer y aplicar esta tasa a las eléctricas como fuente

36. OrTiZ,C. (2003). El periódico de Extremadura,01/11/2003.

37. Torres, R. (2015). El periódico de Extremadura 24/03/2015. Nos robaron las tierras, las vegas, el futuro. Nos roban la electricidad, los beneficios de sus rentas, los impuestos que generan y, nos dejaron la nuclear. Le usurparon el Tajo a Extremadura y nos expoliaron. 
de ingreso extraordinario para mejorar la condición económica y medioambiental de las provincias productoras de energía eléctrica.

La finalidad del canon es compensar a las provincias /regiones productoras: Castilla y León, Galicia, Extremadura, Aragón, Castilla La Mancha etc, por el daño medioambiental que producen sus instalaciones. En la práctica, el impuesto recae casi exclusivamente en las grandes presas hidroeléctricas. Canon energético que es una necesidad para fomentar y mantener el desarrollo rural, las empresas ubicadas en las distintas comarcas y fomentar el turismo de embalses como factor de mejora económica y generación de empleo ya que las presas emplean a pocas personas y la riqueza de su explotación apenas revierte en sus zonas de influencia. En Galicia, segunda Comunidad Autónoma generadora de energía hidroeléctrica sólo se emplea a 500 personas. Energía renovable, limpia pero fluctuante en función de las precipitaciones. Agua embalsada que sirve también para la refrigeración de las centrales nucleares de Tarragona (Ascó, del río Ebro), Guadalajara (Trillo, del río Tajo), como en Cáceres (Almaraz, del pantano de Arrocampo en el Tajo cacereño). Central en manos de Iberdrola con el $53 \%$, Endesa el $36 \%$ y Gas Natural, 11 11\%, que en el año 2014 ha producido $15.795 \mathrm{MKw} / \mathrm{h}$, el $6 \%$ del consumo eléctrico nacional, un 1,2\% menos que en año 2013, superando a las dos unidades de la central de Ascó, que ha producido $14.537 \mathrm{MKw} / \mathrm{h}$.

En cambio, el precio de la electricidad en los hogares españoles aumentó un $52 \%$ entre el segundo semestre de 2008 y el mismo período de 2014, lo que supuso un crecimiento de 81 euros en el megawatio por hora (MWh), casi el doble de los 42 euros por MWh de la media de los 28 países de la Unión Europea. Inconvenientes siempre presentes que soportan las provincias/ regiones sin recibir ninguna compensación económica, ya que se paga por la electricidad el mismo precio que las provincias consumidoras y no productoras.

Un modelo de desarrollo productivo herencia del franquismo que legó a la democracia. «Poder de las eléctricas que permanece y constituye un serio problema económico de trascendencia política. Otros países de la UE han nacionalizado una industria que es esencial para la economía del país ${ }^{38}$. España, país de favorables condiciones para el desarrollo de la industria hidroeléctrica (que es la forma más barata de generar electricidad) tiene inconvenientes (sequías) y ofrece posibilidades que se deben aprovechar para el desarrollo económico, social y la calidad de vida de sus habitantes, mejor de los grupos humanos establecidos en los diferentes territorios. Fuente de energía renovable que más se consume en España, 50\%, de gran importancia para la «transición energética» por su responsabilidad ambiental y sostenible para el desarrollo de las provincias productoras y consumidoras de energía eléctrica.

38. Tortella, G. «Energía y poder, pasado y presente». El País 29/12/2013, p. 30. 


\section{CONCLUSIONES}

De lo expuesto se concluye que el gran beneficiado de los desafíos del agua en España ha sido el sector hidroeléctrico por las relaciones que se establecieron entre las empresas privadas y el Estado.

- La política hidráulica hasta 1960 ha tenido como desafío el aprovechamiento del agua para el desarrollo del regadío, factor estratégico de la modernización agraria, la transformación económica, la generación de empleo, la fijación de la población y la vertebración del territorio.

- El paso del agrarismo como motor de desarrollo al proceso industrial centró el interés en la producción hidroeléctrica. En el proceso, las regiones más pobres, donde se concentra el agua embalsada y la producción hidroeléctrica, que debían haberse beneficiado de los efectos favorecedores de los regadíos, vieron relegado sus intereses en favor de las regiones más ricas, hacia donde se ha enviado la energía eléctrica producida y, con ella, los beneficios económicos, la generación de empleo, el desarrollo industrial y la expansión de los servicios.

- La industria hidroeléctrica está emplazada en los lugares de propicias condiciones físicas, desde los cuales puede luego transportarse al mercado que la reclama. Se ha favorecido, por parte del Estado, a las regiones prósperas frente a impulsar el desarrollo de los territorios que alberga los embalses y las nucleares. Por ello, se deben establecer mecanismos que modifiquen las desigualdades producidas en el equilibrio económico de las regiones para beneficiar mediante compensaciones a las provincias productoras.

- El canon energético desaparecido en 1986, como factor compensatorio, fue tardío en su aplicación, escaso de recursos monetarios pagados, y no ha solucionado el desequilibrio económico y social entre las provincias productoras y consumidoras de energía eléctrica. Se volvió a reclamar desde el año 2001, pero estando aprobado desde finales de 2012 todavía no se ha aplicado por las trabas que ha encontrado en su desarrollo.

- La previsible disminución de recursos de agua por el cambio climático obligará, como desafío, a coordinar la planificación hidrológica y gestión de los recursos hídricos renovables con la territorial, agraria, industrial, urbanística etc, para garantizar el desarrollo local, la equidad social y la protección del medioambiente.

- La sociedad, los técnicos y los políticos deben resolver, favorablemente, las necesidades de riqueza y bienestar para las generaciones actuales sin afectar a la demanda futura de agua para los diferentes usos. 